\section{A imprevisibilidade democrática}

SANTOS, Wanderley Guilherme dos. A democracia impedida: o Brasil no século XXI. Rio de Janeiro, Editora FGV, 2017. 187 páginas.

\section{Juarez Rocha Guimaráes}

Professor da Universidade Federal de Minas Gerais (UFMG).

E-mail: <juarezrg15@gmail.com>.

\section{Marcelo Sevaybricker Moreira}

Professor da Universidade Federal de Lavras (UFLA).

E-mail: <marcelomoreira@dch.ufla.br>.

DOI: $10.1590 / 339716 / 2018$

Há mais de cinquenta anos, Wanderley Guilherme dos Santos (doravante WGS) mantém-se absolutamente atuante na cena intelectual brasileira. Esta resenha divide-se em duas partes: a primeira busca compreender as raízes de $A$ democracia impedida em sua obra, compreendendo este livro como uma revisão e atualização crítica de sua obra voltada para o desafio da construção da democracia no Brasil; a segunda parte busca identificar os conteúdos principais e marcar as conquistas analíticas deste livro recém-lançado.

Professor formador de várias geraçôes de graduandos e pós-graduandos em ciências sociais, participante da última geração do Iseb (Instituto Superior de Estudos Brasileiros), fundador do Iuperj (Instituto Universitário de Pesquisas do Rio de Janeiro), da Anpocs (Associação Nacional de Pós-Graduação em Ciências Sociais) e da revista $D a$ dos, autor de aproximadamente trinta livros, além de inúmeros artigos, capítulos e textos jornalísticos, WGS é talvez um dos poucos dentre seus pares que dispensa apresentação.

Não por razões meramente quantitativas. A sua trajetória está associada à formulação de importantes teses sobre o Brasil e sobre a política em geral. Vejamos alguns exemplos. Dois anos antes da deflagração do golpe militar, ele, um jovem militante da esquerda universitária brasileira, escreveu um panfleto político no qual conclamava as forças populares a se unirem contra o golpe em curso no país. O panfleto político Quem dará o golpe no Bra- sil? ficaria na memória nacional como uma espécie de texto visionário a respeito dos eventos que marcariam nossa história. Na sua tese de doutoramento em Stanford (Estados Unidos), publicada como Sessenta e quatro: anatomia da crise (Santos, 1986), formulou inusitada hipótese de interpretação do golpe de 1964, qual seja, a de que ele teria sido resultado de uma "crise de paralisia decisória", combinando fragmentação da representação partidária no Congresso Nacional com radicalização ideológica e alta rotatividade ministerial. Essa tese representava importante contraponto às análises então existentes sobre o golpe de 1964, como as de Alfred Stepan, Celso Furtado e Hélio Jaguaribe, que o tomavam como decorrência de fatores econômicos e sociais, compreendendo as instituiçóes políticas como variáveis dependentes. De modo geral, ela é representativa de um conjunto de escritos, típicos de uma primeira geração de cientistas políticos formados na matriz da ciência política estadunidense e que, através de sofisticada análise empírica, enfatizava o potencial explicativo da dinâmica política, procurando delimitar, ao mesmo tempo, o campo próprio dessa "nova" ciência no Brasil e diferenciá-la dos estudos sobre política feitos por pesquisadores das áreas do direito, sociologia, economia, entre outras. Em 1979, WGS publicaria outro clássico das ciências sociais brasileiras, Cidadania e justiça (Santos, 1979). Nele, o autor assevera que o padrão de restringir diretos civis e políticos e conceder direitos sociais - inaugurado por Getúlio Vargas nos anos de 1930 - se repetia nos anos de chumbo da ditadura pós-1964, controlando, por meio da regulação estatal, o conflito entre capital e trabalho. Era o que ele denominava de "cidadania regulada", outro termo que, assim como "paralisia decisória", se incorporaria ao jargão da ciência política brasileira. A ideia de cidadania regulada se opunha a leituras que compreendiam o legado varguista como algo a ser extirpado do país. Embora não ignorasse os efeitos nocivos desse legado ao sistema de representação democrática, WGS sustentava que a política social varguista se constituía em uma reação viável diante de circunstâncias tão adversas de construção do Estado-nação, de integração social e de conflito distributivo. Assim, ele polemizava, nos anos de 1990, contra aqueles que via no desmonte do EsRBCS Vol. 33 n 97/2018: e339716 
tado varguista conditio sine qua non da modernização do Brasil. Ao contrário, diria ele anos mais tarde em $O$ ex-Leviatã brasileiro (Santos, 2006), era imprescindível expandir o Estado mínimo para garantir eficácia à ação estatal e universalizar os direitos mínimos da população brasileira. Um quarto e último exemplo: nos anos de 1990, o Brasil parecia ter superado o interregno autoritário, a "ordem regulada”, consolidando aqui uma sociedade civil complexa com eleiçôes regulares, idôneas e competitivas. WGS, em diversos textos do período, como em Razóes da desordem (Santos, 1993), se perguntava: Por que, então, a democracia brasileira não funcionava adequadamente? Ao contrário do que dizia a quase totalidade dos analistas àquela época, para ele o problema não estava propriamente nas instituiçóes políticas, mas sim na falta de cultura cívica e na sociabilidade hobbesiana dominante entre nós, como já denunciara Oliveira Vianna há décadas, autor frequentemente revistado por WGS. Embora não tenha desenvolvido sistematicamente uma análise da cultura política do país, WGS publicou diversos escritos tentando demonstrar que, no que concerne aos atributos mínimos de uma democracia de massas, o país vinha muito bem, obrigado. Não eram, portanto, as reformas políticas (como cláusula de barreira e voto distrital, por exemplo) que iriam resolver os problemas da sociedade brasileira. Muito ao contrário: elas poderiam gerar efeitos não previstos pela opinião pública, diminuindo a competição pelo poder, como desejavam os neo-oligarcas, que viam seus privilégios ameaçados com a democratização em curso no país nos anos de 1990. Rotatividade e intensa disputa para os cargos eletivos, elevadíssima inclusão político-eleitoral, entre outros fatores, foram apresentados exaustivamente para demonstrar o que ele chamava de "expansão cívica", um processo que teria rompido definitivamente com o padrão oligárquico do Brasil republicano. Se o autor estava certo em seu último diagnóstico, formulado por quem se esmerava em coletar e analisar dados sobre a política brasileira há cinco décadas, ${ }^{1}$ como explicar agora a crise da democracia vivenciada a partir do impeachment dramático da ex-Presidenta Dilma Rousseff?

\section{Atualizaçóes e conquistas}

Talvez, para tentar responder a essa indagação, WGS tenha lançado mais um novo livro. A democracia impedida retoma algumas teses já apresentadas, mas certamente inova noutros pontos, que provavelmente constituirão novas agendas de pesquisa de WGS , bastante profícuo no auge dos seus mais de oitenta anos de idade. Do livro, o primeiro, terceiro e quarto capítulos são, por assim dizer, uma reiteraçáo e um desenvolvimento de argumentos antigos do autor, agora trazidos à baila em um novo contexto.

No primeiro, WGS salienta a proximidade frequentemente ignorada entre democracias e oligarquias. Considerando que ambos são sistemas representativos, o que as distingue é que, sendo escassa a competição no caso das oligarquias, torna-se mais ou menos previsível o seu resultado, ao passo que nas democracias, por ser intensa, o resultado é imprevisível. Assim, a democracia deixa de ser pensada simplesmente por oposição ao autoritarismo (sistema não representativo), não mais tido como o único golpe de morte contra ela. A restrição da elevada competição política, marca das poliarquias (conceito adotado por WGS em sua obra para se referir aos regimes democráticos efetivamente existentes), pode se dar não somente através da limitação do número de votantes (o que, a partir do século XX, tem um custo altíssimo, pois pressuporia um retrocesso em relação ao sufrágio universal), mas também pelo que WGS chama número dos elegíveis (Santos, 1998). As poliarquias, lembra ele, são um produto de um processo histórico não calculado, desencadeado a partir da competiçáo limitada das oligarquias, mas com uma dinâmica qualitativamente distinta e um fenômeno "recentíssimo" na história da humanidade. Mas, ainda no primeiro capítulo, WGS vai além de reiterar o já dito, pois, se referindo ao impedimento de Dilma, o autor define o ocorrido:

[...] ao contrário de golpes militares - que, se bem-sucedidos, buscam desde logo consolidar as condiçóes que os protegeram, desalojando os oficiais opositores de posiçóes de poder e introduzindo, pela força física, se necessária, 
as modificaçóes propícias à estabilização -, os golpes parlamentares em democracias representativas dispensam a liderança e a violência institucional escandalosa, armada ou jurídica (p. 16).

Golpes parlamentares, como os que ocorreram no Paraguai, Honduras e no Brasil no início do século XXI, procuram manter a rotina institucional inalterada, mas modificam o sentido das políticas adotadas pelo poder governante. Cumpre notar uma profunda mudança na tônica dos argumentos do autor quando se compara os seus textos dos anos de 1990 com A democracia impedida, a despeito de o autor se valer do mesmo marco teórico. Se antes a principal ameaça à democracia brasileira parecia ser a limitação da competição eleitoral pelo controle dos elegíveis, agora, o perigo que corremos é de outra natureza. Golpes parlamentares parecem se constituir num risco permanente às democracias representativas do século XXI: “o Brasil não restará solitário no conjunto de golpes parlamentares com bênção constitucional" (p. 187). A democracia brasileira, antes tão bem-avaliada por WGS, mostrou-se, na segunda década deste século, mais frágil do que o autor pensara. $\mathrm{O}$ livro, nesse sentido, parece uma tentativa do autor de fazer um "acerto de contas" com seus próprios juízos formulados no passado próximo.

No terceiro capítulo, WGS volta-se também a argumentos conhecidos pelos seus leitores. Pensando nos conflitos distributivos de uma ordem competitiva, ele afirma que, enquanto as democracias são compatíveis com as mudanças aceleradas típicas de sociedades industriais, as oligarquias só podem funcionar normalmente em situações de conservadorismo social. Ele distingue, então, dois tipos de situaçôes pelas quais podem passar as democracias: a da instabilidade produtiva e da estabilidade improdutiva:

[...] trata-se da interação conflito/cooperação em que os participantes, empenhados em vitórias pontuais, não ultrapassam o limite que assegura a reprodução do status quo regulamentado, isto é, aquele no qual a disputa distributiva permanecerá legítima em momentos posteriores (p. 71).
No caso de instabilidade produtiva, há uma melhora das condiçóes de vida de pelo menos um dos participantes, sem degradar as condições da posição do oponente, o que pode ocorrer de diversos modos, entre eles quando há um progresso concomitante das condições dos participantes, ou quando os subalternos progridem mas não tanto quantos os participantes do estratos sociais superiores. No caso da estabilidade improdutiva, as condiçōes materiais de vida dos subalternos ou mantém-se as mesmas ou se degradam. Não seria a "Nova República" um caso de instabilidade produtiva, instabilidade essa aparentemente bem processada até há pouco pelas instituições do país?

No quarto capítulo, o autor procura novamente reforçar a tese de que, posteriormente à redemocratização, o país vivenciou um extraordinário processo de "conversão cívica", frequentemente negligenciado por aqueles que partiam de um diagnóstico de uma crise da representação política no mundo contemporâneo. Em O paradoxo de Rousseau (Santos, 2007), WGS já questionava esse diagnóstico, tanto aplicado aos países de tradição democrática mais longeva, quanto, e especialmente, referido ao Brasil. Contudo, ponderando sobre as teorias da modernização, ele sugere, na medida em que o conflito político ampliado é tornado legítimo pela democracia, ser razoável supor que essa sociedade torna-se mais susceptível a crises.

Com o alargamento do direito do voto, multiplicando-se a natureza das demandas e estabelecidos os direitos de associação e manifestação de opiniāo, a continuidade de um sistema de governo estritamente por troca de apoios entre os que governam e parte dos que são governados ficou ameaçada (p. 121).

Seria o golpe de 2016, então, o resultado paradoxal do processo de "expansão cívica"? Para WGS, não porque não funcione bem, mas precisamente porque a democracia não pode atender a todas as demandas que consente, é que o golpe se "constitui um dos desenlaces possíveis de processos críticos derivados da ecologia política das sociedades capitalistas" (p. 128). Há que se ressaltar que, a despeito das diferenças contextuais entre a obra recém- 
-publicada e os textos do final dos anos de $1990 \mathrm{e}$ da primeira década dos anos 2000, há uma linha de continuidade argumentativa na obra de WGS: ele já identificara uma tensão inerente às democracias de massa em textos anteriores, tensão essa, agora, explorada a respeito do golpe parlamentar. Parafraseando Robert Michels, segundo o autor brasileiro, a "lei de ferro da insatisfação poliárquica" assegura que:

\section{[...] quanto mais heterogênea a sociedade e homo-} gênea a classe politica, maior o paradoxal hiato entre a adesáo à mecânica da democracia e o repúdio à sua operação poliárquica; ou quem diz democracia, diz insatisfação democrática (Santos, 1998, p. 217, grifo do autor).

Ou seja, nas democracias, o número de potenciais insatisfeitos é sempre maior que o número daqueles que têm sua demanda atendida.

Dizer que esses três capítulos do livro retomam ideias já elaboradas pelo autor em obras anteriores não significa reduzir a sua importância, quer como argumentos tomados isoladamente, quer como partes razoavelmente integradas deste livro. Entretanto, é nos outros três capítulos $(2,5$ e 6$)$ que esse mesmo leitor se surpreenderá com novas teses formuladas por esse conhecido autor.

No segundo capítulo, WGS procura comparar os golpes de 1964 e de 2016 a partir da categoria de ecologia política. Embora existam várias semelhanças entre esses dois contextos (a moralização da política em torno de escândalos de corrupção, uma campanha midiática contra os governantes do Executivo federal, a reação elitista contra a melhoria das condiçóes de vida de setores subalternos promovida por governos trabalhistas etc.), WGS recorre a essa ideia para asseverar que a ecologia política de 1964 era subdesenvolvida quando comparada à de 2016. Essa diferença se constata pelo grau de urbanização (em 1960, dos 73 milhôes de habitantes, apenas $45 \%$ da populaçáo vivia em zona urbana, contra $81 \%$ em 2010, de uma populaçáo total de 195 milhôes), pelo tamanho do eleitorado (que em 1962 era composto de aproximadamente de 18 milhóes de eleitores contra os 135 milhóes em 2010) e, por fim, pela mobilização social (incrivelmente maior e mais diversificada no século XXI, com mais organizaçóes sindicais, empresariais, religiosas, de defesa dos direitos humanos etc.). Precisamente por isso, a natureza do golpe contra Dilma não pode ser a mesma do que depôs Jango. Por decorrência lógica, as estratégias de luta pela recomposição do pacto político democrático não podem ser as mesmas, sugere WGS.

Mais uma vez, esse autor, como notório intelectual público que é, depois de mais de meia década de trabalho na ciência política, posiciona-se contra as possibilidades de retrocesso democrático e cívico no país. Se, nas décadas de 1960, 1970 e 1980, esse retrocesso assumia a forma de uma ditadura civil-militar e, nos anos de 1990, a forma de propostas de reforma das instituiçóes políticas democráticas ao lado do desmonte do Estado brasileiro sob a alegação de sua suposta modernizaçáo, agora é o golpe parlamentar o fenômeno novo e relativamente desconhecido a ser enfrentado.

O quinto capítulo inicia-se com expressiva sentença:

[...] não sei em que extensão mundial a tese é verdadeira, mas no Brasil nem os liberais morrem de amores pela democracia, nem os empresários são apaixonados pelo livre-mercado (p. 129).

A tese do autor é de que o golpe parlamentar, "filho bastardo" da democracia no século XXI, colocou o Brasil na onda reacionária do capitalismo neoliberal, ainda que com o atraso de quase uma década, através da revogação de direitos e do desmonte do Estado de bem-estar (aqui, já bastante limitado). Trata-se de um interessante capítulo, no qual WGS procura integrar a análise da política doméstica às dinâmicas mais recentes do capitalismo internacional, movimento reflexivo e argumentativo nem sempre realizado com o mesmo empenho pelo autor nas suas obras anteriores.

No sexto e último capítulo, o leitor se defronta com um texto que procura demonstrar que o golpe parlamentar de 2016 só se tornou possível mediante a violaçấo do conjunto das regras constitucionais e que essa violaçáo teve início em 2012, com o julgamento da Ação Penal (AP) 470, o chamado "mensalăo". O papel do Judiciário nas democracias contemporâneas, 
objeto central deste capítulo, é talvez um elemento estranho e a maior novidade para o leitor acostumado com a trajetória de WGS, embora o juízo condenatório de WGS sobre o papel político do STF já fosse conhecido (pela coletânea de textos publicados em $\grave{A}$ margem do abismo [Santos, 2015]). Para WGS, a fraude constitucional cometida pelo STF no julgamento do "mensaláo" pode ser resumida em três pontos. Em primeiro lugar, "o sequestro do poder constituinte do povo", isto é, quando se aceitou o juízo formulado pelo relator da AP 470, Joaquim Barbosa, de que a "Constituição era aquilo que o STF diz que ela é" (Santos, 2017, p. 168). Ao contrário, somente o povo, em assembleia universal ou representativa, lembra WGS, pode dizer o que é a Constituição. $\mathrm{O}$ segundo ponto diz respeito à "disjunção epistemológica entre ser inocente e não ser culpado" (p. 170). No processo, exigiu-se dos réus que comprovassem sua inocência, isto é, que demonstrassem a ignorância do crime, o que só poderia ser feito, contraditoriamente, conhecendo o próprio crime. $\mathrm{O}$ contorcionismo retórico e epistemológico produzido pelos ministros do STF fez que, por falta de provas, se condenasse os acusados numa "sensacional modalidade de prestidigitação" (p. 174). O terceiro ponto refere-se à interpretação dada pela Corte à teoria do domínio do fato, de acordo com a qual quanto mais alta fosse a posição hierárquica do réu, maior a facilidade dele para destruir provas contra si, o que os levou a votar pela sua culpabilidade. WGS vaticina que as três violaçôes da lógica e da Constituição farão que, no futuro, os analistas estudem a AP 470 como "um julgamento de exceção" (p. 178). Levando em conta o "mensaláo" e acrescentadas a campanha midiática sistemática contra os governos de Lula e Dilma e as manifestaçóes de rua de 2013 e de 2015, tem-se, ao cabo, um cenário para o golpe de 2016. Criou-se uma fratura social que viabilizou o consórcio golpista, que "não foi parido de nenhuma conspiração à altura do vocábulo", mas sim "da convergência de vetos de agentes políticos relevantes” (p. 182). Da capacidade de mobilização dos setores golpeados, bem como da habilidade e da viabilidade em se costurar acordos e prover benefícios aos partícipes do golpe, depende, alerta WGS, o futuro imediato da democracia nacional.

Podemos nomear quatro grandes conquistas conceituais e analíticas de $A$ democracia impedida e identificar a importância histórica desse livro na cultura política brasileira.

A primeira delas é a de fixar, no campo da ciência política, o conceito de "golpe parlamentar”. Distinto da caracterização mais geral de golpe civil, centrado na identificação dos atores imediatos da interrupção da democracia, fenômeno exclusivo das democracias representativas, podendo ocorrer tanto em regimes presidencialistas ou parlamentaristas, o golpe parlamentar necessitaria de uma cobertura ativa do Poder Judiciário para legitimar-se e traz uma inerente instabilidade em sua dinâmica. Para WGS, se o golpe parlamentar no Brasil não é paradigmático, ele não é um estranho ao horizonte das democracias destes inícios do século XXI.

A segunda grande conquista conceitual é a de inscrever o golpe parlamentar em uma interpretação de longo alcance, tanto histórica como internacional, pegando no contra-pé visóes institucionalistas correntes da ciência política, acomodadas a uma expectativa de estabilidade ou a uma teleologia, tão típica das teorias da modernização, de um progresso contínuo da ordem democrática. $\mathrm{O}$ que resulta dessa interpretação é que estamos, no interior de uma narrativa de alcance secular sobre a formação das democracias, em um período histórico certamente instável das tensóes próprias da democracia, de seu jogo permanente de absorção e institucionalização dos conflitos em sociedades altamente complexas e cujo "potencial de escolhas irracionais no mundo contemporâneo adquiriu considerável enriquecimento". Se a imprevisão é democrática, o conflito está em suas entranhas, mas é, como se nos dissesse o autor, como se estivéssemos entrando em zonas de grave turbulência.

A terceira conquista é a de integrar, talvez como nunca antes em tal intensidade na obra deste autor, a democracia aos rumos do conflito distributivo no capitalismo. Nas trilhas de Karl Polanyi, WGS afirma, de forma concisa, que entre democracia e capitalismo há um pas de deux, mas essa contradição em movimento parece ter sido rompida pelo

[...] terremoto provocado pelo sistema financeiro norte-americano que agrediu todas as economias do mundo, saudáveis ou não. 
$[\ldots]$

Nenhuma época anterior a que se classifica atualmente como liberal testemunhou uma ordem de dominação tão nua de propósitos conciliatórios com os segmentos dominados. (pp. 123 e 130).

Se "a igualdade no capitalismo é um ponto de fuga”, após a crise de 2018 o tempero da solidariedade foi substituído pela voracidade do interesse imposta por minorias capitalistas. Isto é, a relação entre democracia e igualdade deveria voltar ao centro da análise e das perspectivas das teorias democráticas.

A quarta conquista, que resulta das três anteriores, é a de afirmar com humildade que estamos "na lavoura arcaica do conhecimento". Isto é, diante de fenômenos novos de tal intensidade e magnitude, não cabe uma teoria democrática ciosa de sua normalidade, mas urge provocar uma nova agenda de pesquisa, teórica e empírica, que reorganize conhecimentos e expectativas normativas realistas. Cumpre lembrar que WGS, há décadas, vem salientando a postura prudencial na análise política do ceticismo moderado: o autor define essa postura epistemológica pelo reconhecimento de duas proposiçóes. A primeira é a de que a ordem social, sendo marcada pela reflexividade e subjetividade dos atores envolvidos, é regulada por um sistema de causalidades relativamente estável, mas, por outro lado, aberto a variaçóes autônomas e imprevisíveis. Nesse sentido, "a ordem social não é, mas produz-se" (Santos, 1979, p. 13). A segunda proposição é a de que toda investigação sobre o mundo social implica a desconsideração de vários aspectos e a avaliação daqueles que foram privilegiados. Destarte, pode-se afirmar que, aliado aos fatos específicos da precocidade da experiência democrática e do parco saber produzido sobre ela, WGS assume como premissa que qualquer conhecimento que venha a ser produzido sobre a democracia é insuficiente, e, por conseguinte, passível de revisão. Não seria $A$ democracia impedida um exercício de revisão e atualização crítica desse autor à luz dos imprevistos desdobramentos da recente poliarquia brasileira?
Mas talvez, mais do que ainda por essas razóes, este livro seja lembrado como uma peça de resistência democrática inscrita na alta cultura política brasileira. Na bela tradição de amor ao povo brasileiro, que organiza a coerência de toda a sua obra, WGS denuncia as razões das tradições demofóbicas, que hoje atualizam as suas vozes. Pois mesmo a esperança da democracia precisa ter suas razóes.

\section{Notas}

1 Mais do que isso, WGS foi responsável por criar índices para a análise política, como o de competitividade eleitoral, que mede a relação candidatos por número de vagas em Votos e partidos: almanaque de dados eleitorais (Santos, 2002).

\section{BIBLIOGRAFIA}

SANTOS, Wanderley Guilherme dos. (1962), Quem dará o golpe no Brasil? Rio de Janeiro, Civilização Brasileira.

SANTOS, Wanderley Guilherme dos. (1979), Cidadania e justiça: a politica social na ordem brasileira. Rio de Janeiro, Campus.

SANTOS, Wanderley Guilherme dos. (1986), Sessenta e quatro: anatomia da crise. São Paulo, Vértice.

SANTOS, Wanderley Guilherme dos. (1993), Razóes da desordem. Rio de Janeiro, Rocco.

SANTOS, Wanderley Guilherme dos. (1998), “Poliarquia em 3D". Dados, 41 (2): 207-281.

SANTOS, Wanderley Guilherme dos. (2002), Votos e partidos: almanaque de dados eleitorais Brasil e outros paises. Rio de Janeiro, Ed. FGV.

SANTOS, Wanderley Guilherme dos. (2006), O ex-Leviatá brasileiro: do voto disperso ao clientelismo concentrado. Rio de Janeiro, Civilização Brasileira.

SANTOS, Wanderley Guilherme dos. (2007), O paradoxo de Rousseau: uma interpretação democrática da vontade geral. Rio de Janeiro, Rocco.

SANTOS, Wanderley Guilherme dos. (2015), $\grave{A}$ margem do abismo: conflitos na politica brasileira. Rio de Janeiro, Revan. 


\section{ERRATA}

RBCS vol.33 no 97/2018

DOI: $10.1590 / 339700 / 2018 \mathrm{ER}$

E-location: e339700ER

- Nos artigos: "O comitê de articulaçáo federativa no governo Lula: os percalços da cooperação territorial"; "Marcuse crítico de Weber: a política no capitalismo tardio"; "Representação política: a virada construtivista e o paradoxo entre criação e autonomia"; "O pequeno investidor na bolsa brasileira: ascensão e queda de um agente econômico"; "Ciências humanas e neurociências: um confronto crítico a partir de um contexto educacional"; "A peculiaridade do maquiavelismo inglês: das origens ao século XVII"; "Internacionalização de micro, pequenas e médias empresas inovadoras no Brasil: desafios do novo paradigma de desenvolvimento"; "A luta pelo reconhecimento e o paradigma da dádiva: uma proposta de articulação teórica" e "Determinantes individuais e de contexto da simpatia partidária na América Latina", assim como nas resenhas: "Um acerto de contas com o judiciário argentino", "A imprevisibilidade democrática" e "Idle No More: sobre a mobilização indígena no Canadá", publicados na Revista Brasileira de Ciências Sociais, 2018, volume 33, número 97, cujos e-locations são respectivamente: e339703, e339704, e339705, e339710, e339702, e339706, e339708, e339709, e339711, e339715, e339716 e e339717, os prefixos do DOI estáo incorretos.

Onde se lia: "10.590"

Leia-se: "10.1590". 